\title{
XXVI. Remarks on the formula for the dispersion of light
}

\section{Rev. Baden Powell M.A. F.R.S.}

To cite this article: Rev. Baden Powell M.A. F.R.S. (1836) XXVI. Remarks on the formula for the dispersion of light, Philosophical Magazine Series 3, 9:52, 116-119, DOI:

$10.1080 / 14786443608648960$

To link to this article: http://dx.doi.org/10.1080/14786443608648960

册 Published online: 01 Jun 2009.

Submit your article to this journal

Џ Article views: 2

Q View related articles $₫$ 
XXVI. Remarks on the Formula for the Dispersion of Light. By the Rev. Baden Powell, M.A., F.R.S, Savilian Pro. fessor of Geometry, Oxford.

[Continued from vol. viii. p. 309.]

$I^{\mathrm{N}}$ $\mathrm{N}$ a former portion of these papers I have given some account of the methods by which the formula of dispersion, or relation between the length of a wave and the velocity of its propagation, or the refractive index for a given ray and given medium, is made applicable in calculation. I have also illustrated the comparison made by the researches which $\mathrm{Sir} \mathrm{Wm}$. R. Hamilton has given me between that formula in its simpler, but consequently only approximate, form, and the exact development. In the present instance, in continuation of the same object of facilitating the study of this highly interesting portion of the science of light, my design is, besides some general remarks, to furnish certain constant elements which enter into all calculations by the exact method; together with one more instance of the comparison of this method with the approximate one from the same source.

The exact method, in fact, consists in this: The relation is expressed by the series of powers of the reciprocal of $\lambda$ resulting from the division of the development of the sine by the arc, with certain indeterminate coefficients. In the approximate method these are supposed all constant and equal, and are expressed by a common factor. In the exact development this cannot be allowed; but an investigation is given by which they are, in fact, eliminated; and there results a method for obtaining the theoretical index which is equivalent to the enunciation of a law expressing the connexion of the index of any one ray for a given medium, with three others supposed assumed: thus successively each of the four remaining of the seven standard rays have their indices found: or, in another point of view, we may say, that (taking three terms of the series) there are three constants to be found from observations. These depend on the medium; when we eliminate them therefore it is in effect equivalent to assuming three of the indices given by observation.

The very name of an approximate method commonly conveys the idea of a shorter and simpler process. In the present instance, however, the case is quite otherwise. On looking at the analysis contained in my former papers the exact method might appear long and intricate, but in fact the precess of calculation is much simpler than might at first sight be imagined, and shorter than in the approximate method. The whole consists in the determination of the two constants log. 
Remarks on the Formula for the Dispersion of Light. 117

$a$ and $\log . b$ for each ray, and the differences of the indices of the assumed rays, which constitute the other factors in the equation (26.), (Lond. \& Edinb. Phil. Mag. for March 1836). That equation in a general form for finding the index of any

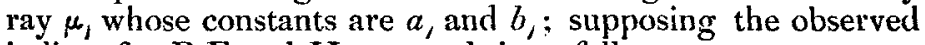
indices for B F and $\mathrm{H}$ assumed, is as follows :

$$
\mu_{1}-\mu_{\mathrm{F}}=a_{1}\left(\mu_{\mathrm{F}}-\mu_{\mathrm{B}}\right)+b_{1}\left(\mu_{\mathrm{H}}-2 \mu_{\mathrm{F}}+\mu_{\mathrm{B}}\right)
$$

The following values of $\log . a_{1}$ and $\log . b_{l}$ have been given in the foregoing paper,

$$
\begin{aligned}
& \log a_{\mathrm{D}}=\overline{\mathrm{1}} \cdot 80441 \\
& \log b_{\mathrm{D}}=\overline{\mathrm{1}} \cdot 06281
\end{aligned}
$$

I have also received the following from the same source,

$$
\begin{aligned}
& \log a_{\mathrm{G}}=\overline{1} \cdot 74345 \\
& \log b_{\mathrm{G}}=\overline{\mathrm{1}} \cdot 63384
\end{aligned}
$$

It is easy to determine values of the same constants for the other rays which remain to be found, viz. $\mathrm{C}$ and $\mathrm{E}$. They are deduced by the formulas (analogous to those in the former paper, Eq. 15. 27. \&c.),

$$
\begin{aligned}
& t_{1}=\frac{\tau_{1}^{-2}-\tau_{\mathrm{B}}^{-2}}{\tau_{\mathrm{H}}^{-2}-\tau_{\mathrm{B}}^{-2}} \\
& a_{1}=-\left[1-2 t_{1}\right] \\
& b_{1}=-t_{1}\left[1-2 t_{1}\right] .
\end{aligned}
$$

By substituting the values of $\tau$ from Fraunhofer's observations, we readily obtain,

$$
\begin{aligned}
& \log a_{\mathrm{c}}=\overline{\mathrm{1}} \cdot 95433 \\
& \log b_{\mathrm{c}}=\overline{2} \cdot 65253 \\
& \log a_{\mathrm{E}}=\overline{\mathrm{1}} \cdot 49646 \\
& \log b_{\mathrm{E}}=\overline{\mathrm{1}} \cdot 03196
\end{aligned}
$$

With these logarithms, and those of the other factors in the

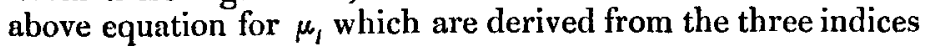
$\mu_{\mathrm{B}} \mu_{\mathrm{F}} \mu_{\mathrm{H}}$ assumed from observation for the particular medium, we thus get immediately the values of $\mu_{1}$ for the other rays resulting from the exact formula of theory.

It would be easy to give examples of this method; but for the present $I$ shall confine myself to stating the results obtained by it for the ray G in Fraunhofer's media; compared, 
as before, with the approximate results of my former compttation, performed by methods which will now be wholly superseded.

\begin{tabular}{|c|c|c|c|c|}
\hline \multicolumn{2}{|l|}{ Medium. } & $\begin{array}{c}\mu_{G} \\
\text { Observed by } \\
\text { Fraunhofer. }\end{array}$ & $\begin{array}{c}\mu_{G} \\
\text { Caleulated } \\
\text { by the exact } \\
\text { formula. }\end{array}$ & $\begin{array}{c}\mu_{G} \\
\text { Calculated } \\
\text { by the approxi- } \\
\text { mate formula. }\end{array}$ \\
\hline Flint-glass & 13. & $1 \cdot 6603$ & $1 \cdot 66066$ & $1 \cdot 6609$ \\
\hline Do. & 23. & $1 \cdot 6588$ & $1 \cdot 65910$ & $1 \cdot 6582$ \\
\hline Do. & 30. & $1 \cdot 6554$ & $1 \cdot 65569$ & $1 \cdot 6551$ \\
\hline Do. & 3. & $1 \cdot 6308$ & $1 \cdot 63101$ & $1 \cdot 63$ I 3 \\
\hline Crown-glass & M. & $1 \cdot 5735$ & $1 \cdot 57368$ & $1 \cdot 5738$ \\
\hline Do. & 13. & $1 \cdot 5399$ & $1 \cdot 54001$ & $1 \cdot 5399$ \\
\hline Do. & 9. & $1 \cdot 5416$ & $1 \cdot 54182$ & $1 \cdot 5416$ \\
\hline Oil of turpen & ine. & $1 \cdot 4882$ & $1 \cdot 48833$ & $1 \cdot 4886$ \\
\hline Solution of po & tash. & $1 \cdot 4126$ & $1 \cdot 41272$ & $1 \cdot 4126$ \\
\hline Water. & & $1 \cdot 3413$ & $1 \cdot 34140$ & $1 \cdot 34.13$ \\
\hline
\end{tabular}

The preceding method enables us to calculate the indices for $\mathrm{C}, \mathrm{D}, \mathrm{E}$ and $\mathrm{G}$, supposing those for $\mathrm{B}, \mathrm{F}$, and $\mathrm{H}$ assumed. It may, however, be desirable, for rendering the comparison of any case with theory complete and satisfactory, to possess the means of calculating likewise the indices for $\mathrm{B}, \mathrm{F}$, or $\mathrm{H}$, assuming three others, or generally any index. For this purpose we must have recourse to the more general form (21.). This will not, in fact, be found more complex or difficult in practice, notwithstanding the simplification obtained by introducing the particular relation subsisting between $\tau_{\mathrm{F}} \tau_{\mathrm{B}}$ and $\tau_{\mathrm{H}}$ on which the process above given depends. I shall therefore here add such a statement of the more general method as may be necessary for the object in view, and likewise furnish those constants which are independent of the particular medium, and necessary for the computation.

The formula (21.) may be expressed, for brevity, thus:

$$
0=\left(\mu_{\mathrm{D}}-\mu_{\mathrm{B}}\right) k-\left(\mu_{\mathrm{F}}-\mu_{\mathrm{B}}\right) l+\left(\mu_{\mathrm{H}}-\mu_{\mathrm{B}}\right) m,
$$

and the coefficients $k l m$ which are independent of the medium are readily found from Fraunhofer's values of $\tau_{B} \tau_{D} \tau_{F} \tau_{H^{*}}$ From these values we have directly

$$
\begin{array}{ll}
\tau_{B}^{-2}=15 \cdot 489 & \tau_{D}^{-2}=2 l \cdot 135 \\
\tau_{F}^{-2}=31 \cdot 075 & \tau_{H}^{-2}=46.666,
\end{array}
$$

and by means of these we obtain for the coefficients in (21.) the following values: 


$$
\begin{aligned}
& \log k=3 \cdot 87943 \\
& \log l=3 \cdot 65263 \\
& \log m=3 \cdot 94185
\end{aligned}
$$

In any particular medium then, taking the logarithms of the differences of the three indices, we easily obtain the fourth by the above formula.

For the corresponding relation of the other rays we must take $a$ formula analogous to (21.), which will be as follows:

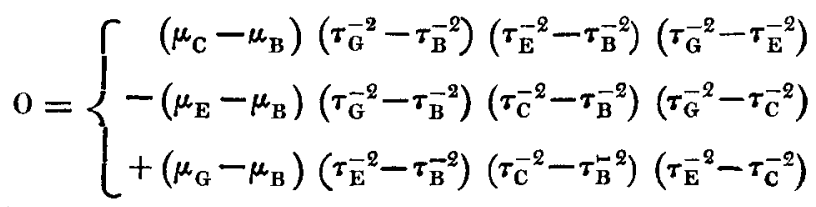

which for brevity may be written as before,

$$
0=\left(\mu_{\mathrm{C}}-\mu_{\mathrm{B}}\right) k^{\prime}-\left(\mu_{\mathrm{E}}-\mu_{\mathrm{B}}\right) l^{\prime}+\left(\mu_{\mathrm{G}}-\mu_{\mathrm{B}}\right) m^{\prime} .
$$

The coefficients $k^{\prime} l^{\prime} m^{\prime}$ may be found exactly as before from Fraunhofer's values of $\tau_{B} \tau_{C} \tau_{E} \tau_{G}$ which give

$$
\tau_{\mathrm{C}}^{-2}=17 \cdot 045, \quad \tau_{\mathrm{E}}^{-2}=26 \cdot 437, \quad \tau_{\mathrm{G}}^{-2}=39 \cdot 705 .
$$

By means of these we obtain

$$
\begin{aligned}
& \log k^{\prime}=3 \cdot 54623 \\
& \log l^{\prime}=2 \cdot 93137 \\
& \log m^{\prime}=2 \cdot 28794 .
\end{aligned}
$$

I will only add at present that I am now engaged in determining by observation the indices for various media, especially those of a highly dispersive nature: and in the few attempts as yet made to verify the theory in these cases, (in which it is manifestly put to a more severe test than in any of the cases hitherto given,) I have found the method just explained by far the most preferable. The approximate method in any form appears to me at once more troublesome and less satisfactory. The values of the constants applicable to all media above given, may be useful to those who may engage in such calculations, or in verifying those already performed by other methods.

Oxford, June 19th, 1836. 